\title{
La formación de profesores/as de inglés como intelectuales: algunas anotaciones epistemológicas
}

\section{The training of English teachers as intellectuals: some epistemological annotations}

\author{
Juan Carlos Vásquez García ${ }^{1}$ \\ Facultad de Educación, Universidad de Antioquia
}

Resumen: El presente texto aborda, de manera reflexiva, un proceso gnoseológico posible en la formación de profesores de inglés intelectuales. Para ello, se recurre a la investigación narrativa y a la narración de sí, como puentes entre la conciencia de masas y la autodeterminación necesaria para descubrir problemas existenciales y desarrollar el deseo y las capacidades para resolverlos. Se concluye que la narración de sí en la formación de docentes, a través del abordaje de narrativas literarias y/o científicas, y la respectiva discusión a la luz de la realidad de la cual surge y de textos académicos que permita interpretarla puede ser una estrategia posible por medio de la cual los/as futuros/as docentes pueden desarrollar prácticas pedagógicas liberadoras, que haga de ellos/as docentes intelectuales.

Palabras clave: epistemología, formación de docentes, intelectuales, pedagogía

\begin{abstract}
This text reflexively addresses a possible gnoseological process in the training of intellectual English teachers. For this purpose, narrative enquiry and self-narrative are used as bridges between mass consciousness and the self-determination necessary to discover existential problems and to develop the desire and skills to solve them. It is concluded that self-narrative in teacher training, through the approach of literary and/or scientific narratives, and the respective discussion in the light of the reality from which it emerges and of academic texts that allow it to be interpreted, can be a possible strategy through which future teachers can develop liberating pedagogical practices that make them intellectual teachers.
\end{abstract}

Key words: epistemology, intellectuals, pedagogy, teacher education

\section{Introducción}

El término epistemología se deriva de dos raíces griegas, episteme, que significa conocimiento o ciencia, y logos, que significa discurso. Ambas raíces juntas en una sola palabra indican, entonces, que la epistemología se ocupa de, y se preocupa por, entender cómo conocemos, es decir, por comprender los procesos por los cuáles construimos conocimiento, cómo lo validamos, cómo decidimos que un saber es confiable, cómo desciframos que un discurso o procedimiento científico es verídico (Diccionario

\footnotetext{
${ }^{1}$ Docente de cátedra, magíster en educación, licenciado en lenguas extranjeras de la Universidad de Antioquia y, actualmente, estudiante de la especialización en Estudios Afroamericanos y del Caribe, CLACSO y del Doctorado en Filosofía, Universidad Pontificia Bolivariana, Medellín-Colombia. Miembro del Grupo de Investigación Diverser de la Facultad de Educación-Universidad de Antioquia, Calle 70, N. $52-21$. MedellínColombia. E-mail, jcarlos.vasquez@udea.edu.co. ORCID: http://orcid.org/0000-0002-1598-479X.
} 
etimologías.dechile.net). Históricamente, la epistemología ha sido objeto de estudio de filósofos y científicos euro-norteamericanos (Dussel, 2018a; wa Thiong’o, 2017a), cuyos tratados han prescrito y limitado los modos de construir conocimiento oficial a nivel mundial (Viveros, 2018). No obstante, hay estudios recientes y productos de investigación en educación., que muestran a los/as profesores/as como sujetos, éticos y responsables, que piensan su labor como agencia cultural y política que se ubica en un campo en permanente relación y tensión gracias a que en él se encuentran otros individuos o instituciones que se disputan el control de las representaciones y el conocimiento de los individuos para definir emociones, comportamientos y convenciones sociales. Dicho control tiene efectos directos en la organización política y cultural de las comunidades en las cuales las masas habitan. Este reconocimiento ha servido como sustento para afirmar que los/as profesores/as tienen la voluntad, las herramientas y las capacidades cognitivas para construir sus propios edificios teóricos y prácticos sobre su quehacer que contribuyan al acervo científico social existente sobre educación, pedagogía y cultura.

Como se verá a continuación, este escrito intenta contribuir a la comprensión teóricopráctica sobre cómo los individuos pueden llegar a desarrollar prácticas de autodeterminación que desemboquen en una auto-percepción de compromiso con el constante develamiento de dinámicas hegemónicas de dominación y explotación y el desarrollo de estrategias para su transformación. Al mismo tiempo, espero que este sea un ejemplo que sirva a formadores de maestros, en general, y a formadores de docentes de inglés, en específico, de cómo la formación crítica y ética de los/as estudiantes debe conjugar y propiciar la exposición a narrativas externas y propias para el alcance de una mentalidad liberadora que les permita observar, analizar, criticar, evaluar y valorar la realidad desde perspectivas plurales y no únicamente desde perspectivas unilaterales (Freire \& Shor, 2014; Dussel, 2018a).

Para lograr este propósito, recurriré a lo que he denominado como narración de sí, propia de la investigación narrativa (Bruner, 2002) y del psicoanálisis (González, 2018), como método para descentrar al sujeto, es decir, para moverlo de narrativas dominantes e intentar conectarlo con la producción de sus propias interpretaciones producto de su experiencia particular. De esta manera, las construcciones discursivas particulares y los discursos hegemónicos globales encuentran un espacio de conversación y debate por medio del relato narrativo. Para esto, he elegido presentar mi experiencia educativa como objeto de estudio, en la cual describo el proceso que he vivido para convertirme en un profesor que reconoce que puede ejercer poder en una sociedad neoliberal en la cual el análisis y la acción individual y colectiva no son promovidas; todo lo contrario, son silenciadas si dicho análisis y acciones están dirigidas al logro de cambios sustanciales en términos de justicia social, económica y epistémica. De igual manera, se observará cómo dicha investigación autobiográfica ha servido para ejercer la enseñanza como un acto de compromiso social con la comunidad que busca, a través de la labor pedagógica, propiciar formas de relación plurales basadas en el entendimiento y el respeto.

\section{El problema}


Este texto se deriva del trabajo de investigación que desarrollé para culminar mis estudios de maestría ${ }^{2}$ en educación cuyo enfoque metodológico fue autobiográfico narrativo y en el cual indagué, por medio de un análisis documental, por el rol que la literatura y la pedagogía crítica tenían, hasta el año 2015, en los documentos oficiales, tales como, la autoevaluación institucional, modelo pedagógico y el plan de estudios, que el departamento en el cual me formé desarrolló para preparar docentes de inglés y francés. Gracias a este enfoque de investigación me topé con la categoría teórica que Giroux (1997) construyó sobre los profesores como intelectuales cuya labor no sólo es enseñar un contenido, que es neutro y a-histórico, o a través de un método de enseñanza, que impacta efectiva y eficazmente la calidad del aprendizaje de los/as aprendices, sino que también se ocupa de reflexionar sobre todos aquellos mecanismos y estrategias, evidentes y ocultas, presentes en la cultura de masas que influyen sobre la cognición y, por ende, las representaciones, el comportamiento y acciones de quienes aprenden. Si bien el autor no se ocupa específicamente de los/as profesores/as de lenguas como intelectuales, dichos desarrollos son importantes, ya que como docente no he pasado por alto que nuestra labor está sujeta a los trabajos teóricos y decisiones que investigadores universitarios o burócratas de instituciones del Estado toman con base en ellos, haciendo de la labor docente una mera experiencia técnico-burocrática que, para ser exitosa, debe cumplir al pie de la letra con ciertos requisitos y procedimientos impuestos y no consensuados. Además, al indagar sobre esta categoría teórica en el campo de la enseñanza de lenguas me topé con concepciones similares, pero no iguales, a la de Giroux, en las cuales los/as docentes son nombrados como autónomos, críticos, educadores en lengua extranjera u descoloniales.

Si bien la literatura explorada coincide en que hay un interés en lograr que los/as docentes de lenguas reconozcan que pueden tener control sobre su labor y pueden tomar decisiones sobre ella en el aula de clase, todos concuerdan en que tanto el control como las decisiones tomadas giran en torno al método de enseñanza. Igualmente, encontré que hay un consenso en cuanto a la labor crítica en la enseñanza de lenguas, la cual se enfoca sólo en develar patrones de manipulación ideológica por medio del lenguaje en la cultura de masas. Finalmente, observé que si bien los/as autores/as elegidas afirman que los programas de formación docente deben apuntar a formar educadores/as intelectuales que piensen y reflexionen sobre sus acciones en el aula de clase y cómo dicha labor influye en la organización política de un territorio, sociedad o comunidad, ninguno/a elabora sobre cómo los/as docentes podrían llegar a convertirse en uno/a.

Aquí, entonces, me ocupo de entender el proceso gnoseológico que alguien podría transitar para convertirse en un/a profesor/a intelectual, que me aventuro, por medio de este escrito, con base en elementos metodológicos de la investigación narrativa para señalar dicho camino. Este camino que me propongo señalar no es una receta, ni mucho menos, pero sí un esfuerzo por analizar las experiencias que me han traído y comprometido por el camino de la justicia social y cognitiva. Por esta razón, recurriré a eventos autobiográficos, que marcaron mi vida privada, y a literatura académica, la cual me enseñó a ligar los

\footnotetext{
${ }^{2}$ El informe de investigación del cual se desprenden las reflexiones aquí presentadas se titula $; Y$ si $1+1=3$ ?: La literatura como alternativa metodológica y la pedagogía crítica como marco teórico y práctico en la formación de profesores y profesoras de inglés y francés en una universidad pública de Colombia. Resultado de un análisis documental con un enfoque biográfico-narrativo de la Facultad de Educación-Universidad de Antioquia. Medellín-Colombia.
} 
sucesos de mi historia privada con los procesos históricos mundiales (Dussel, 2018a) para comprender la vida cotidiana en términos glocales (El Saadawi, 2018) e intentar transformarla a través de mi labor como profesor en la educación formal y en la vida cotidiana como ciudadano, hijo, amigo, etc. Al final, concluiré que el proceso para convertirme en un profesor intelectual no sólo necesita ejercitar la razón, sino también los sentidos y las emociones. Además, postulo que es necesario superar la concepción de que es un requisito sine qua non para el profesor como intelectual adherirse a un movimiento social, ya que existen diferentes formas de hacer activismo, estar comprometido con el conocimiento, la realidad y la comprensión y transformación de totalidades vigentes.

\section{La narración de sí en la investigación auto-biográfica}

\subsection{El enfoque autobiográfico narrativo}

La narración de sí, propia de la investigación narrativa, sirvió como instrumento para descubrir y contraponer la conciencia y la memoria (González, 2018; Arfuch, 2010). A través de ella, el ejercicio de la memoria en conjugación con las emociones que ella genera, la palabra surge como producto que permite problematizar la conciencia y, en consecuencia, producir, contrastar, comprender e interpretar una experiencia como producto de diferentes realidades, una hegemónica y la otra subalterna. La conciencia, entonces, se muestra como producto de la hegemonía cuyas manifestaciones son las representaciones normalizadas que se muestran como olvido, alienación, saber, mientras que la memoria se muestra $<<$ como el no-saber que conoce, el lugar de inscripciones que restituyen una historia que no fue escrita > (González, 2018; 568). Por un lado, la conciencia es la experiencia del saber institucionalizado; por otro lado, la memoria es la experiencia del saber periférico no escrito en la historia oficial, por lo tanto, un saber olvidado. Con estos dos conceptos en mente, la narración de sí en la investigación narrativa surge como un dispositivo que hace uso del recuerdo, la emoción y la palabra para negociar significados particulares, propios del individuo, y universales, propios de la cultura. Aquí, la dialéctica deseo y ley se encuentran para de-construir y re-significar la cultura en la cual el sujeto se encuentra inmerso.

Con la narración autobiográfica como enfoque de investigación es posible postular que "escogiéndome a mí mismo, escojo al hombre" (Sartre en Greene, 1995; 92). Con esto, quiero decir que las narraciones permiten poner sobre la mesa eventos relevantes, constitutivos de la experiencia y de las opciones tomadas, para estudiar y comprender los discursos oficiales que subyacen a ellos. Dichos discursos se presentan como construcciones histórico-sociales, geopolíticamente localizados que pueden ser externos a la voluntad propia de quienes los implementan, que son producidos por personas que ostentan el privilegio de ejercer su poder e influencia por medio del mercado de valores y bienes, las instituciones financieras, los medios de comunicación y las instituciones políticas. En la investigación narrativa, los discursos sancionados oficiales, y no oficiales, se pueden interpretar, como lo proponen Tuider (2012), Greene (1995), Mendoza et al. (2010) y Huchim \& Reyes (2013), como trabajos de ficción que sirven para dar sentido a la realidad de que son partícipes, al cosmos (Dussel, 2018a). Es así, que la investigación narrativa propone que lo dicho, mencionado o narrado no debe quedarse sobre el papel y el análisis del discurso, ya que ella sería, entonces, objeto de análisis terapéutico, sino que debe servir como excusa para ir a la fuente de su producción y propagación para 
comprender la situación problemática en primera persona, para así desarrollar interpretaciones que propicien un cambio real tanto en los actos de habla, como en el comportamiento de los participantes. En este método, además, los criterios de validez y confiabilidad, que todo método de investigación demanda, no están sujetos a criterios de universalidad y generalización, sino que se enfocan en criterios de claridad, verosimilitud y transferibilidad (Connelly \& Clandinin, 1995). Así, los relatos producto de las experiencias aquí contadas e investigadas adquieren una importante dosis estética para el/la lector/a, que les permitirán decidir en qué medida se identifican y cómo la narración ayuda a evaluar la experiencia propia para generar cambios subjetivos y objetivos en la práctica docente.

\subsection{La conciencia}

Durante la investigación mencionada anteriormente me di cuenta de que mis expectativas, y futura experiencia, como docente no sólo estuvieron marcadas por la asistencia a los cursos que me preparaban como docente, en los cuales se hacía hincapié en lo crucial que es tomar en cuenta las <<necesidades $>>$ de los/as aprendices para lograr procesos efectivos y eficaces, sino también por la historia propia, privada, de la cual soy portador. Mi formación, entonces, se vio marcada por las expectativas institucionales, las del público a quienes ofrecía mi servicio y mis propias expectativas. Estas últimas se manifestaban en forma de malestar, ya que no me gustaba lo que hacía ni lo que me pedían hacer en los programas de curso ni observaba que mis estudiantes estuvieran realmente convencidos de lo que se proponía en clase. Algunos, incluso, años más tarde han manifestado estar hartos de tomar cursos de lenguas porque siempre se proponen los mismos juegos y actividades cuyo enfoque sólo es mejorar aspectos formales de la lengua. En otras palabras, era infeliz y no disfrutaba lo que hacía. De hecho, una pregunta presente todo el tiempo en mi quehacer cotidiano como maestro era, ¿y de qué manera estoy contribuyendo a mejorar las condiciones cognitivas, emocionales y materiales de mis estudiantes al enseñar las partes de la casa en inglés? Aquí, es importante aclarar que en el ambiente político y cultural que habito, la percepción general que las personas tienen sobre la educación e ir a la escuela es la de que ellas ayudarán a mejorar la calidad y condiciones de vida. Por esta razón, me preguntaba todo el tiempo por cómo estaba contribuyendo con la enseñanza del inglés al proyecto de vida de mis estudiantes que apuntaba a escalar en la sociedad. Vale aclarar, igualmente, que el consenso popular con el que me he topado durante mis años como profesor sobre la percepción de una mejor vida gira en torno al alcance de una mejor posición económica y social. Sin duda, la percepción actual sobre escuela, educación y vida han estado sujetas a las dinámicas económicas neoliberales que han acaparado la atención de los medios de comunicación masivos (Torres, 2006; Giroux, 1997, 2003) y que han determinado las representaciones de la cultura de masas (Dussel, 2018a).

No obstante la percepción compartida por las masas acerca de una vida buena, de la cual fui partícipe, no era feliz y vivía angustiado y lleno de preocupaciones. Los síntomas que sufría no se debían a deficiencias netamente económicas y materiales. En Colombia, los/as profesores/as de inglés gozamos de mejor prestigio y reputación que los/as profesores/as de otras áreas, ya que se dice que quienes logramos aprender una o dos lenguas más debemos ser muy inteligentes, brillantes y debemos contar con una memoria prodigiosa; por esto, desde antes de graduarme del pregrado contaba con condiciones laborales que me permitían sortear y satisfacer necesidades materiales primarias. Además, 
la preponderancia que la política local le ha dado al aprendizaje de inglés como segunda lengua ha disparado la demanda de docentes en esta área. La angustia, preocupación e insatisfacción de la cual era preso se debía a aspectos de mi vida privada que, por prejuicios, estereotipos y diferentes manifestaciones de violencia física y simbólica en la sociedad que habito, prefería mantener fuera de la esfera pública. Mi orientación sexual nohegemónica podía ser objeto de burla, ridiculización o mala fama como ocurría con estudiantes a quienes enseñaba y otros colegas con quienes trabajaba. Me rehusaba a experimentar esto, lo cual causaba otro tipo de luchas, esta vez, internas, tales como baja autoestima, vivir siempre con miedo y temor de ser descubierto, entre otros.

Fue la violencia simbólica, y física en algunas ocasiones, de la cual eran objeto mis estudiantes, cuya identidad u orientación sexual y de género era no-hegemónica, la situación que me llevó a preguntarme e incomodarme por mi rol como educador que media entre un presente turbio y un futuro mejor. Dicha incomodidad me llevó en mi deseo de mejorar la calidad de vida, esta vez en términos intelectuales, de mis estudiantes a abordar la enseñanza, en un primer momento, como un espacio en el cual se abordaba la literatura para, a partir de allí, tratar asuntos sociales problemáticos que afectaran nuestra tranquilidad y sosiego. Esta forma la aprendí de un profesor de la universidad que dictó un curso sobre literatura y cuentos cortos en el pregrado. Su objetivo principal era que aprendiéramos sobre la riqueza filosófica, sociológica e histórica que la literatura encierra. La corrección lingüística quedó relegada a un segundo plano. Él fue la razón por la cual descubrí mi amor, olvidado, por la literatura y empecé a abordar asuntos históricos y sociológicos, con base en ella, en mis clases de inglés.

Para ser honesto, nunca estuve conforme con mi formación como docente de inglés, ya que siempre observé que dicha formación estaba dirigida a producir técnicos de la enseñanza de la lengua, expertos en aspectos formales de la misma, pero nunca hubo mención de la importancia de contenidos, diferentes a los lingüísticos, y su influencia en la formación de las representaciones que las personas desarrollan sobre su realidad (Dussel, 2018b).

Volver sobre estas escenas de mi vida en la cual diferentes esferas públicas, tales como la familiar, la laboral, la cultural y la cívica, entre otras, se conjugaban y ejercían influencia sobre mi quehacer como docente y ciudadano, en un ejercicio de investigación enmarcado en un paradigma crítico, en el cual la autodeterminación es el objetivo y más grande logro, para propiciar acciones de cambio producto de reflexiones propias, en un lugar y tiempo específicos, me han ayudado a pensarme como un agente cultural (Giroux, 1997) que se reconoce en desventaja histórica y territorial (Segato, 2007) como persona y como miembro de un colectivo continental conquistado, asesinado, saqueado y difamado (Grosfoguel, 2016), cuya labor no reside sólo en hacer parte de y sucumbir a la división social y económica del trabajo (Adorno, 1976), que cumple una labor sólo para recibir un cheque, sino que piensa, analiza, evalúa e implementa cambios en los contenidos curriculares. Esto último lo trataré más adelante.

\subsection{La memoria}

El apartado anterior permite observar grosso modo cómo mi experiencia docente estuvo marcada por tres momentos que se interrelacionan al momento de tomar decisiones.

Empero, hay un malestar personal que hace de mi labor docente una experiencia incómoda, porque no sentía que como profesor realmente estuviera contribuyendo, en términos 
epistémicos, a mejorar las condiciones de vida de mis estudiantes. Es decir, el conocimiento transmitido no contribuía al desarrollo del entendimiento de que, por ejemplo, hay, y ha habido en la historia y diferentes culturas, orientaciones sexuales diversas diferentes a la heterosexual, lo que daba licencia a mis estudiantes, por decirlo de alguna manera, para hacer comentarios peyorativos o burlas en torno al tema. Al respecto, Giroux (1997) y Mclaren (2002), afirman que los temas abordados en clase tienen un impacto político en tanto influyen en las dinámicas sociales que los individuos establecen entre sí. El malestar, no obstante, se refería a una incomodidad propia, transversal, que articulaba mi experiencia privada, mi vida como estudiante y mi vida como profesional.

\subsubsection{Experiencia privada: ser un niño homosexual}

Mientras crecía, recuerdo que me enseñaron a obedecer y seguir las convenciones tal y como eran. No se me permitía cuestionarlas, debatirlas o rechazarlas. Esto, a su vez, daba lugar a luchas internas que se convertían en comportamientos agresivos hacia los demás, en aislamiento, en autoinfligirse. Las convenciones, tal y como se me presentaban, eran inmóviles, inmutables y sagradas. En caso de que alguien no las siguiera, sería etiquetado como pagano, rebelde, criminal, basura humana, que debía ser reformada en asilos, prisiones, hospitales o iglesias, o eliminada. Fui abusado de niño, y luego humillado públicamente por el violador cuando decidí no sucumbir a su voluntad nunca más. Por su culpa fui conocido como un chico pervertido y despreciado por ser lo que era, una atrocidad pública, un homosexual, pero aún más que eso, un chico afeminado. Gracias a este suceso siento que no se me dio la oportunidad de explorar mis propias preferencias sexuales: la gente se reía de mí, me maltrataba y me aislaba. Este recuerdo me ha perseguido toda la vida. Este recuerdo es la razón por la que pasé de niño y adolescente, y sigo pasando, de adulto, por tantas fases. Cuando me sentía atrapado e incomprendido era antisocial y agresivo. Cuando quería ser respetado era el que haría cualquier cosa para ser reconocido públicamente por sus habilidades, destrezas y, lo más importante, su virilidad. Cuando quería ser aceptado públicamente, querido y amado por mis amigos heterosexuales, cisgénero y cisexuales, era el que actuaba amablemente y fingía que le gustaba el sexo opuesto. Despreciaba y temía a los demás homosexuales. Este recuerdo me ha llevado a travesías de auto-odio y baja auto-estima, pero también de auto-sanación. Todavía surgen conflictos internos porque sé, en lo más profundo de mi ser, que aún queda mucho camino por recorrer. A pesar de los avances sociales, políticos y legales de la diversidad sexual y de género durante las últimas tres décadas, sé que seré minimizado por no ser lo suficientemente hombre, por no sentir ningún tipo de atracción hacia el sexo opuesto. Como hombre adulto, el sistema educativo, la tecnología educativa impuesta a los profesores o las instituciones públicas y privadas y los medios de comunicación me recuerdan constantemente que soy un <<otro〉> que debe ser salvado, aceptado, sin ser realmente respetado, por ser un "diferente". Pero yo no quiero ser simplemente un-otro. Quiero ser yo. Quiero que me conozcan como Juan y no como <<Juan el homosexual >> o $<<$ Juan el rarito $>>$, porque ser un hombre homosexual es sólo una de las cosas que soy, pero no todo lo que puedo ser.

\subsubsection{Ser un estudiante}


Sólo hasta ahora me doy cuenta de que, si no hubiera sido por la literatura, estaría muerto. Especialmente, si no hubiera sido porque leí El extranjero, de Albert Camus, no habría aprendido a cuestionar las convenciones, o Nétochka Nezvánova, de Fiódor Dostoyevski, no habría aprendido que estaba bien tener sentimientos románticos por los chicos. Si no hubiera sido por Skins, no habría aprendido que podía ser aceptado, respetado y amado de verdad por la gente sin importar mi orientación sexual. La literatura y sus diferentes expresiones me ayudaron a verme de forma diferente. No fui un gran lector en mi infancia o adolescencia. No obstante, a la edad de 16 años, sólo un libro bastó, El extranjero de Albert Camus, para alivianar un poco el caos interno que vivía por la carga de expectativas familiares respecto de conseguir una pareja romántica del sexo opuesto. A esa edad, y sin realmente saberlo, porque ni en el colegio ni en la universidad leímos o discutimos sobre la potencia de la literatura (Eagleton, 2013; Rosenblatt, 2002), la literatura me enseñó que las cosas, tal y como son, pueden cambiar cuando nos lo proponemos. La literatura me enseñó, y aún lo hace, tal como lo confirma Nussbaum (2010), que lo que se considera "diferente" puede ser considerado "normal" una vez que la historia de fondo es conocida por grupos de personas, tal como sucede en Billy y el vestido rosa de Anne Fine (1994). Aunque se ha comprobado, y he aprendido, que la literatura expande nuestra imaginación y libera nuestra mente apelando a las experiencias, sensaciones, situaciones, sentimientos de sus lectores a través de sus personajes, preguntas, problemas y temas en los que basa sus historias (Aghagolzadeh \& Tajabadi, 2012; Eagleton, 2013; Ellison, 2010; Goshn, 2002; Greene, 2005; Rosenblatt, 2002), también puede encajonarlas (Rosenblatt, 2002). Rosenblatt (2002) y Greene (2005) afirman que cualquier tema que se aborde en la literatura que leemos tiene el poder de liberar nuestro potencial imaginativo, pero esto siempre dependerá de cómo los profesores enseñen a sus lectores a leer los textos. Estas autoras sostienen que a través de la literatura podemos enseñar a nuestros alumnos a basarse en sus historias para interpretar la literatura. En este sentido dicen que todas las interpretaciones son válidas si hay evidencias en el libro, es decir, si los alumnos pueden citar en el libro fragmentos que les ayuden a apoyar su punto de vista. Esto significa que los contenidos por sí solos no son suficientes, sino que es necesario pensar en estrategias que ayuden a las personas a basarse en su propia historia para interpretar los acontecimientos y apoyarlos con hechos que den validez a sus interpretaciones.

En la universidad tuve un profesor que dictaba un curso llamado $<<$ Cuentos $>>$. Este curso me recordó cuán potente la literatura puede llegar a ser en la vida de las personas, ya que ella, por medio de las situaciones personales y colectivas de los personajes, ayuda a sus lectores/as a reflexionarse en relación y tensión con su contexto y circunstancias. Ella ofrece estrategias (Eagleton, 2013), sin realmente ofrecerlas, para abordar dilemas sin ser prescriptiva o recetaria, pero ofrece el lenguaje y la capacidad de los personajes para resolver sus conflictos por medio de un uso abundante de él, que no fueran posibles si no fuera por las palabras.

\subsubsection{Ser un profesor}

Como profesor de inglés en formación me enseñaron que sólo debíamos preocuparnos por seguir los planes de estudio de las instituciones en las que íbamos a trabajar. Hasta ahora, y a pesar de renovaciones curriculares, ellas sólo se centran en lograr que sus estudiantes aprendan aspectos formales de la lengua, algo de vocabulario en contexto y consideran el Pensamiento Crítico sólo como una herramienta que debe utilizarse 
únicamente para traer variedad metodológica, no temática, al aula de clase. Una vez que empecé a trabajar como tal, me di cuenta de que mis alumnos y sus padres me veían como un mago; mis colegas, amigos y superiores me veían como un técnico cuyo único trabajo era llevar juegos y hojas de trabajo a clase para que mis alumnos aprendieran a comunicarse a través de tareas comunicativas que, de este modo, ayudarían a recrear casos de uso del inglés en la vida real en mi clase. Pero me sentía vacío. Estas expectativas me parecían tontas, inútiles y molestas. Tenía otras preocupaciones e intereses. Daba clases a personas cuyas existencias estaban bombardeadas por problemas éticos, morales y económicos. Esta situación me molestaba porque sentía que lo que los planes de estudio proponían no les ayudaría a resolver sus problemas. Tampoco me ayudaban a mí a resolver los míos. Así que empecé a cuestionar la enseñanza de lenguas extranjeras y sus metas y objetivos. ¿La enseñanza de lenguas extranjeras sólo servía para que la gente avanzara profesionalmente? ¿Y los contenidos (explícitos e implícitos)? ¿Qué hay sobre presentar en mis clases ideas que aborden problemas sociales de la cotidianidad que les ayuden a profundizar en sus propias historias para pensar, crear y proponer soluciones a sus problemas existenciales? Una vez más, me vi atrapado. Las teorías de la educación lingüística sólo se preocupan por los objetivos lingüísticos, no por los contenidos. O cuando se preocupan por los contenidos, sólo se preocupan de que los profesores se aseguren de que los alumnos aprenden las formas de la lengua correctamente.

Como se puede evidenciar, en la formación de profesores y ciudadanos, que estén en capacidad de reconocer problemas para abordarlos, comprenderlos e interpretarlos y luego resolverlos, es importante, sino necesario, que la formación esté permeada por la continua incorporación y uso de productos culturales, tales como libros de literatura, poesía, obras de teatros, cuentos cortos, películas, entre otros, que pongan en escena personajes en medio de circunstancias desfavorables a una existencia digna, que se presten para discusiones, debates, reflexiones personales y colectivas que despierten la curiosidad y el deseo de aprender por la vida y para su vida (Vásquez, 2021).

\section{Los intelectuales públicos}

He encontrado que el término intelectual está caracterizado por una polifonía de significados que atribuyen a su labor diferentes formas de expresión y representación en el ámbito cultural. Aun así, estas voces ratifican su compromiso político con la sociedad de la cual hacen parte donde por medio de sus reflexiones buscan develar para el público general las formas en que el poder actúa. Por ejemplo, Bourdieu (en Oliva, 2017) considera que un/a intelectual articula ideas y reflexiones en el medio escrito con el objetivo de legitimarse como pensador. Said (mencionado en Oliva, 2017), por un lado, afirma que el/la intelectual desarrolla sus reflexiones de manera situada y, por otro lado, el mismo autor (mencionado en Giroux, 2003) asevera que debe convertirse en un <<extranjero>> que postula y suscita debates que, al parecer, nadie quiere sostener. Igualmente, Hall (mencionado en Giroux, 2003) sostiene que un/a intelectual aborda problemas urgentes y perturbadores en la vida pública de la manera más rigurosa posible. En misma esta línea, Havel (mencionado en Giroux, 2003) y wa Thiong'o (2017b) nutren la idea anterior con la premisa de que un/a intelectual, por medio de su pensamiento, promueve la solidaridad 
mutua, la tolerancia, los derechos humanos y denuncia los abusos de autoridad, opresión y desigualdad.

\subsection{Los profesores como intelectuales}

Los profesores como intelectuales son una figura teórica desarrollada por Henry Giroux (1997) en su obra del mismo título. En ella, el pedagogo aboga por que los/as profesores/as sean reflexivos y tomen posición en su participación del proceso educativo, de los cuales son protagonistas, en el aula de clase. Allí, el autor insta a los/as profesores/as a analizar y develar la racionalidad que se esconde detrás del currículo y las prácticas de enseñanza aceptadas, los libros de texto que ellos/as y sus estudiantes deben seguir en sus clases, la autoridad que ellos/as practican en su cotidianidad escolar, el lenguaje utilizado en los procesos de enseñanza y aprendizaje, el rol de las esferas públicas, tales como las dinámicas del mercado, la publicidad, la iglesia, la familia, los medios masivos de comunicación, entre otros, en la educación de la población. Insta, además, a que los educadores intelectuales sean provocadores, que toman posición, frente a eventos controversiales (Giroux, 2003). Finalmente, el pensador expresa la necesidad de incluir las experiencias particulares de los/as aprendices en la experiencia escolar para que esta se convierta en un acontecimiento educativo; no obstante, el autor no ilustra cómo esto puede ser logrado.

Respecto de esta categoría conceptual, en el campo de la enseñanza y aprendizaje de las lenguas extranjeras autores/as como Usma (2007), González (2007), Guerrero (2010), Pishghadam, Zabihi \& Kermanshahi (2012) y Kumaravadivelu (2016) han abordado esta categoría desde diferentes perspectivas, tales como profesores autónomos (Usma, 2007 y González, 2007), profesores críticos (Guerrero, 2010 y Pishghadam, Zabihi \& Kermanshahi, 2012), profesores decoloniales (Kumaravadivelu, 2016) y educadores en lengua extranjera (Pishghadam, Zabihi \& Kermanshahi, 2012). Es de resaltar que todas las concepciones, excepto la denominada como educadores en lengua extranjera, proponen preparar docentes de lenguas que actúen bajo sus propios criterios y consideraciones en el aula de clase. En el caso de los profesores autónomos, esa libertad se practica como la capacidad de elegir o desarrollar métodos, es decir, estrategias procedimentales, de enseñanza y aprendizaje de lenguas. En el caso de los profesores críticos y decoloniales, la libertad consiste en diseñar estrategias que permitan a los aprendices identificar formas de dominación a través del uso del lenguaje en productos de la cultura de masas. Finalmente, los educadores en lengua extranjera son propuestos como aquellos docentes que enseñan la lengua extranjera por medio de contenidos relativos a las ciencias, es decir, enseñan una lengua por medio de la filosofía, la biología, la psicología, entre otros. A propósito, cabe mencionar que esta concepción tiene semejanza con la enseñanza de inglés con propósitos específicos. Es de resaltar que hay un consenso general en esta área de formación profesionales que invita a profesores/as a tomar en cuenta las <<necesidades>> [lingüísticas] de los/ aprendices para propiciar experiencias significativas de aprendizaje.

\subsection{Algunos aportes epistémicos para la formación de profesores intelectuales}

Si bien hay un consenso en la literatura académica acerca de qué es un intelectual o cómo debe actuar un/a profesor/a intelectual, he observado que hay un vacío que no aborda 
los medios, estrategias o mecanismos que pueden ser implementados para llegar a ser uno. Ocoró (2019) y Oliva (2017) coinciden en que el primer paso que han tomado intelectuales públicos para convertirse en uno/a es reconocer su condición de opresión y desventaja. Ellas cuentan, por ejemplo, de qué manera el auto-reconocimiento como cuerpos negros en la esfera educativa y en el ámbito social más amplio han ayudado a diferentes personalidades afro, tales como Manuel Zapata Olivella, para mencionar sólo un caso, a asumir la exploración de opciones discursivas decoloniales para entender y denunciar las dinámicas históricas de discriminación racial, económica y de género en este continente. Igualmente, para lograr ser un intelectual público se ha reconocido la necesidad de pertenecer a un movimiento social (Kumaravadivelu, 2016) para entender y conectarse con las realidades que las personas más desfavorecidas de la sociedad han padecido y luchar codo a codo con ellas por cambios significativos en la administración política de la sociedad. Además, se exhorta constantemente a quienes ejercen la labor de profesores intelectuales a publicar sus textos escritos en revistas especializadas en la cual muestren sus encuentros y reflexiones en la experiencia educativa.

No obstante lo anterior, reconociendo que auto-reconocerse, pertenecer a un movimiento social y publicar ha sido decisivo en alcanzar muchos cambios históricos, mi preocupación ha girado, en la formación de profesores/as, y de la ciudadanía en general, en pensar cómo desde la educación formal se puede contribuir en la formación de sujetos éticos, críticos y comprometidos con la vida y con las realidades que la componen. Por esta razón, he decidido compartir mi experiencia de formación, ya que tanto el autorreconocimiento como la adherencia a movimientos sociales y el atreverse a escribir para publicar son antecedidos por un acontecimiento que he decidido nombrar el despertar a la sensibilidad propia y colectiva. Como se puede observar arriba (Ver sección 3), el autorreconocimiento de mi potencial como agente de cambio en la sociedad que habito, y en la cual me desempeño como profesor de inglés, pasó por la identificación de un problema que me afectaba pero que sólo logré verbalizar hasta la lectura de El extranjero. A pesar de que el libro no fue discutido ni debatido en clase con los/as compañeros/as, la historia me permitió encontrar a alguien que no sentía como yo. Él, en su caso, no lloró por su madre. Yo, en mi caso, no sentía atracción por mi sexo opuesto. En cualquier caso, los dos corrimos el peligro de ser juzgados por nuestras maneras no-hegemónicas de sentir. La literatura, entonces, surgió como un medio que me permitió comprender que hay otros seres que no sienten lo que se supone deben sentir, que no estoy solo. Desde esa lectura, mi paz interior mejoró. Este despertar de mi sensibilidad fue posible gracias a lo que más tarde he conocido como el método transaccional desarrollado por Rosenblatt (2002), que como expliqué antes (Ver sección 3.3.2), propone el abordaje de la literatura para interpretar tanto las obras literarias en relación con las experiencias propias. Así, pues, propongo que la formación de sujetos comprometidos con la vida y las realidades que ellas la componen pasa por un despertar a una sensibilidad que pasa por la exposición a narrativas otras, de subalternos, que puede conducir a un autorreconocimiento que puede manifestarse en el compromiso, público o anónimo, con el análisis, la denuncia de circunstancias que causen dolor y sufrimiento, y con la consecuente transformación de la realidad problemática que mejore la calidad de vida de los seres que habitamos este planeta.

Un ejemplo que pone en escena lo anterior ocurrió en 2019. En este año, ensñé un curso de inglés avanzado en la Facultad de Medicina. El curso se llamaba Atención a los pacientes. El programa del curso indicaba que, como profesor, debía enseñar a mis 
estudiantes la forma correcta de pronunciar enfermedades y medicamentos, escribir fórmulas médicas y dar diagnósticos, entre otros objetivos. Además, proponía modelos de preguntas y afirmaciones que los/as estudiantes debían memorizar. Al analizar el currículo oficial de la formación de médicos, observé que no había cursos específicos que trataran diversidad sexual y de género. Gracias a esta ausencia, decidí buscar contenidos que giraran en torno a la atención a pacientes como a la categoría trans y la homosexualidad. Así abordamos una carta que Leelah Alcorn (2015), una niña trans, escribió antes de suicidarse, en la cual manifestaba la falta de apoyo y aceptación por parte de familiares y amigos respecto de su nueva identidad de género y sexual como los mayores motivos por los cuales cometía un acto tal, entre otros. Bastó esta historia para detonar el interés y compromiso con la participación y cumplimiento de las tareas propuestas en clase, para que los/as estudiantes quisieran saber más sobre el tema y contenidos lingüísticos ajenos a los propuestos en el programa del curso. Según conversaciones informales con ellos, nunca habían abordado un tema tal en una clase de inglés, lo cual les daba una perspectiva nueva sobre su aprendizaje de inglés y su labor como médicos. No basta con criticar el uso del lenguaje sin la ayuda de contenidos, disciplinares, interdisciplinares o transdisciplinares, y no basta con utilizar contenidos sino se utiliza el lenguaje con el propósito de analizarlo, evaluarlo, transformarlo.

\section{Para concluir}

A lo largo de estas páginas he intentado describir el proceso por el cual los/as profesores/as, y la comunidad educativa en general, podríamos convertirnos en intelectuales cuyas características son el compromiso genuino con la identificación de problemas cotidianos que aquejan nuestra existencia, su denuncia y transformación. Creo que es importante manifestar que para ser un intelectual público no es determinante pertenecer a un movimiento social determinado ni tampoco es necesario publicar textos escritos. Respecto de la adherencia a movimientos sociales, al igual que Dubet (2011) he experimentado que cada uno tiene una agenda propia que lucha por imponerla sobre los demás grupos, colectivos o movimientos sociales; con lo cual se corre el peligro de establecer posiciones cerradas y unilaterales, que buscan totalizar con una idea o interés realidades otras. Por lo tanto, estoy de acuerdo con Camus (2018) al considerar que la verdadera rebeldía intelectual es aquella que sucumbe a la mesura, la cual obliga a mirar a través de varios lentes para comprender la pluralidad de posiciones y opresiones ajenas a la propia. Esto lo aprendí a implementar después de que observé que, en la facultad de ciencias naturales y exactas de la universidad donde enseñaba, el tema de diversidad sexual y de género abordado desde la literatura algunas veces no generaba curiosidad, no porque quienes asistían al aula no lo necesitaran o no lo vieran como un problema, sino porque el lenguaje no era de su interés. Todo cambiaba cuando abordada el mismo tema a través de textos que hablaran de epistemología feminista en la ciencia o de sexismo en la ciencia. Temas, además, que son de mi interés académico. Respecto de la publicación exclusivamente escrita, Ferreira (2021) encuentra que en la era de las redes sociales y las plataformas digitales como YouTube, Spotify, SoundCloud, entre otras, los/as intelectuales pueden recurrir tanto a la escritura como a los formatos de video y audio para compartir su articulaciones teóricas, conceptuales y narrativas. 
Además, considero sensato resaltar que una figura tal reconoce que la realidad y la educación se erigen como un campo que está habitado por diferentes agentes que se disputan su control. Para ello, utilizan diferentes mecanismos y estrategias, tales como el deseo (McLaren, 1994) en el caso de la publicidad, y el miedo (Nussbaum, 2017) en el caso de los políticos y los medios de comunicación masivos, o el sufrimiento, la discriminación y el dolor, en el caso de la literatura y la educación. De esta manera, un profesor intelectual se esfuerza por comprender las dinámicas sociales y ejerce la pedagogía como un medio a través del cual el conocimiento no sólo sirve para cumplir con estándares de calidad educativa internacionales (Torres, 2006), sino también para propiciar la emergencia de una sensibilidad y desarrollo de un entendimiento que habilite a los/as aprendices para evaluar sus condiciones actuales en relación con los contenidos abordados en clase. Al respecto, Freire (2014) reflexiona:

Una vez que se opta por la transformación, se pueden llevar al seminario trozos de la realidad. [...] ¡Llevarlos y examinarlos! Se puede hacer eso aun siendo un profesor de biología, sin sacrificar el contenido del programa -un fantasma que espanta a muchos profesores-. [...] Supongamos que llevas un informe del Banco Mundial a un aula de Biología. Si el banco exige austeridad en los préstamos del tercer mundo -precios más altos, salarios más bajos y recortes en el programa social-, los alumnos podrán calcular los efectos de esa medida sobre la dieta familiar. ¿Cuántas calorías menos ingerirán esas personas? ¿Qué alimentos más baratos buscarán? ¿Esa dieta aumentará la tasa de enfermedades y la mortalidad infantil? Todas estas cosas tienen que ver con la <<iluminación>> de la realidad: hacer que los estudiantes comprendan que conocer no es sólo comer conocimiento, y que comer también es una cuestión de política. (p. 80-81)

La libertad, entonces, de la cual se habla en la concepción de los profesores autónomos, que transitan y practican los profesores intelectuales, en general, y los de inglés, en particular, la entiendo como un ejercicio de la razón (Hegel, 1999), la imaginación (Vygotsky, 1997) y la creatividad (Freire, 2014) puestas al servicio de la resolución de problemas que aquejen la existencia. El ejercicio de ellas, en mi experiencia, no puede ocurrir a menos que se utilicen contenidos que lo posibiliten. Así, pues, las narrativas, científicas, literarias o personales emergen como instrumentos que median entre el desarrollo de la sensibilidad de los sujetos y el desarrollo de sus capacidades intelectuales para reconocer y abordar problemas. La formación intelectual de todos/as pasa, entonces, por este reconocimiento no sólo pedagógico, sino también epistémico.

\section{Referencias}

Adorno, T. (1976). Terminología filosófica. España: Taurus.

Aghagolzadeh, Ferdows \& Tajabadi, Farzaneh (2012). A Debate on Literature as a

Teaching Material in FLT. Journal of Language Teaching and Research, Vol. 3 (1), 205-210 
Alcorn, Leelah (2015). LEELAH ALCORN'S SUICIDE NOTE [FULL TEXT]. Recuperado de https://catholictrans.wordpress.com/2015/01/03/leelah-alcorns-suicide-note-fulltext/

Arfuch, L. (2010). Sujetos y narrativas. Acta Sociológica, núm. 53, 19-41

Bruner, J. (2002). La fábrica de las historias. Derecho, literatura y vida. Buenos Aires, Argentina: Fondo de cultura Económica de Argentina, S.A

Camus, A. (2018). El hombre rebelde. Madrid: Alianza Editorial, S.A.

Connelly, M. \& Clandinin, J. (1995). Relatos de Experiencia e Investigación Narrativa, Remei Arnaus, Virginia Ferrer, Nuria Pérez de Lara, F. Michael Connelly, D. Jean Clandinin, Maxine Greene, Déjame que te cuente. Ensayos sobre narrativa y educación (pp. 11-60). Barcelona: Editorial Laertes

Dubet, François. (2011). Repensar la justicia social. Contra el mito de la igualdad de oportunidades. Buenos Aires: Siglo XXI.

Dussel, E. (2018). Filosofía de la liberación. Ciudad de México: FCE

Dussel, E. [Carlos Ometochtzin]. (2018b, 9 de octubre). La transformación de la educación hacia la descolonización de la pedagogía [Video]. YouTube. https://youtu.be/sWg94cBYDrM

Echeverri, J. A. (2008). "Una experiencia pedagógica, formativa y editorial: la Revista Educación y Pedagogía. Entrevista al profesor Jesús Alberto Echeverri Sánchez", director, entrevista por Juan Fernando Saldarriaga Restrepo, Revista Educación y Pedagogía, vol. XX, núm. 50, 13-29.

Eagleton, Terry (2013). El acontecimiento de la literatura. Barcelona, España: Ediciones Península

Ellison, M. (2010). Make them think: Using literature in the primary English language classroom to develop critical thinking skills. EF@BULACOES, 7, 21-31

Ferreira, C. (2021). Black Brazilian Feminisms: From Page, to Stage, to Screen, Review: Literature and Arts of the Americas, 54:1, 34-44, DOI: 10.1080/08905762.2021.1904649

Fine, A. (1994). Billy y el vestido rosa. Bogotá, Colombia: Editorial Santillana S. A.

Freire, Paulo (2012). Pedagogía del oprimido. Madrid, España: Siglo XXI de España Editores, S.A.

Freire, P. (2014). Miedo y osadía. La cotidianidad del docente que se arriesga a practicar 
una pedagogia transformadora. Buenos Aires: Siglo Veintiuno Editores Argentina S.A.

Freire, Paulo (2015). Pedagogía de la esperanza. Madrid, España: Siglo XXI de España Editores, S.A.

Giroux, H. (2003). Pedagogía y política de la esperanza. Teoría, cultura y enseñanza. Buenos Aires: Amorrortu

Giroux, Henry (1997). Los profesores como intelectuales. Hacia una pedagogía crítica del aprendizaje. Barcelona, España: Europa, S.L.

González, A. (2007). Professional Development of EFL Teachers in Colombia: Between Colonial and Local Practices. Íkala, revista de lenguaje y cultura (12), no.18, 309332

Ghosn, Irma (2002). Four good reasons to use literature in primary school ELT. ELT Journal, Vol. 56 (2), 172-179

Greene, M. (1995). El profesor como extranjero en Jorge Larrosa, Remei Arnaus, Virginia Ferrer, Nuria Pérez de Lara, F. Michael Connelly, D. Jean Clandinin, Maxine Greene, Déjame que te cuente. Ensayos sobre narrativa y educación (pp. 81-130). Barcelona: Editorial Laertes

Greene, Maxine (2005). Liberar la imaginación. Ensayos sobre educación, arte y cambio social. Barcelona, España: Editorial GRAÓ, de IRIF, S.L.

Grosfoguel, Ramón. (2016). A estrutura do conhecimento nas universidades ocidentalizadas: racismo/sexismo epistêmico e os quatro genocídios/epistemicídios do longo século XVI. Sociedade e Estado, 31(1), 25-49. https://dx.doi.org/10.1590/S0102-69922016000100003

Guerrero, C. (2010). The Portrayal of EFL Teachers in Official Discourse: The Perpetuation of Disdain, PROFILE Vol. 12, No. 2, 33-49

Hegel, H. G. W. F. (1999). Principios de la filosofía del derecho o derecho natural y ciencia política. Barcelona: Edhasa

Huchim, D., \& Reyes, R. (2013). La investigación biográfico-narrativa, una alternativa para el estudio de los docentes. Revista Electrónica "Actualidades Investigativas en Educación", 13 (3). http://www.redalyc.org/articulo.oa?id=44729878019

El Saadawi, N. [Channel 4 News]. (2018, Junio 13). Nawal El Saadawi on feminism, fiction and the illusion of democracy [Video]. YouTube. https://www.youtube.com/watch?v=djMfFU7DIB8 
Nussbaum, Martha (2019). La monarquía del miedo. Una mirada filosófica a la crisis política actual. Barcelona: Planeta

Kumaravadivelu, B. (2016). The Decolonial Option in English Teaching: Can the Subaltern Act?, TESOL QUARTERLY (50), no. 1, 66-85. doi: 10.1002/tesq.202

Oliva, Elene. (2017). Intelectuales afrodescendientes: apuntes para una genealogía en América Latina. Tabula Rasa, (27), 45-65. Disponible en: https://dx.doi.org/10.25058/20112742.444

Pishghadam, Reza; Zabihi, Reza \& Kermanshahi, Paria (2012). Educational Language Teaching: A New Movement beyond Reflective/Critical Teaching, Life Science Journal, 2012, 9(1), 892-899.

Segato, Rita (2007) La Nación y sus otros. Raza, etnicidad y diversidad religiosa en tiempos de Políticas de la Identidad. Buenos Aires: Prometeo.

Torres, C. (2006). Educación y neoliberalismo. Ensayos de oposición. Madrid, España: Editorial popular.

McLaren, P. (1994). Formación escolar del cuerpo posmoderno: pedagogía crítica y política de encarnación en Peter McLaren, Pedagogía Crítica, resistencia cultural y la producción del deseo (pp. 79-124). Argentina: Instituto de Estudios y Acción Social

Nussbaum, Martha (2010). Sin fines de lucro: por qué la democracia necesita de las humanidades. Buenos Aires, Argentina: Katz Editores

Ocoró Loango, Anny. (2019). Entre la emancipación y la descolonización: tensiones luchas y aprendizajes de los/as investigadores/as negros/as en la educación superior. Revista Práxis Educacional, v. 15, n. 32, 53-68.

Rosenblatt, Louise (2002). La literatura como exploración. México D.F., México: The Modern Language Association, Nueva York

Tuider, Elisabeth (2012). Contando historias/narraciones en un contexto poscolonial.

Análisis del discurso y análisis biográfico como métodos horizontales. En Sarah Corona Berkin, Olaf Kaltmeier (editores), en Diálogo, Metodologías horizontales en Ciencias Sociales y Culturales (pp. 111-136). Barcelona: Editorial Gedisa S. A.

Usma, J. (2007). Teacher Autonomy: A Critical Review of the Research and Concept beyond Applied Linguistics, Íkala, revista de lenguaje y cultura Vol. 12, no.18, 245275

Vásquez, J. (26 de septiembre de 2021). Por una pedagogía desde la vida para la vida. 
Grupo de investigación Diverser. https://grupodiverser.wixsite.com/mysite/post/por-una-pedagog\%C3\%ADa-desde-la-vida-para-la-vida

Viveros Vigoya, Mara (2018). De la "extraversión” a las epistemologías

"nuestroamericanas". Un descentramiento en clave feminista, en Santiago Gómez Obando, Catherine Moore Torres y Leopoldo Múnera Ruiz (eds.) Los saberes múltiples y las ciencias sociales y políticas (pp. 171-192)Bogotá: Universidad Nacional de Colombia

Wa Thiong'o, N. (2017). Desplazar el centro. La lucha por las libertades culturales. Barcelona, España: Rayo Verde Editorial

Wa Thiong'o, N. (2017b). Reforzar los cimientos. Barcelona, España: Penguin Random House Grupo Editorial, S. A. U

Vigotsky, Lev (1997). La imaginación y el arte. México: Fontamara 